\title{
FORMULASI VANISHING CREAM MINYAK ATSIRI SERE (Cymbopogon citratus (D.C) Stapf) DAN UJI SIFAT FISIKNYA SERTA UJI AKTIVITAS REPELAN TERHADAP NYAMUK Aedes aegypti BETINA
}

\section{FORMULATION OF VANISHING CREAM SERE ESSENTIAL OIL (Cymbopogon citratus (DC) Stapf) AND PHYSICAL PROPERTIES ALSO REPELLANT ACTIVITY TESTING AGAINTS FEMALE Aedes aegypti MOSQUITOES}

\author{
Azis Ikhsanudin \\ Fakultas Farmasi Universitas Ahmad Dahlan; E_mail :are_size@yahoo.com; \\ azis.ikh@gmail.com.
}

\section{Abstrak}

Minyak atsiri daun sere merupakan bahan alam yang telah terbukti secara ilmiah mempunyai efek repelan terhadap nyamuk. Penelitian ini bertujuan untuk mengetahui pengaruh konsentrasi minyak atsiri sere (Cymbopogon citratus (D.C) Stapf) dalam basis vanishing cream terhadap sifat fisik dan daya repelan terhadap nyamuk Aedes aegypti betina. Minyak atsiri sere sere (Cymbopogon citratus (D.C) Stapf) diperoleh dengan cara destilasi uap air yang selanjutnya di evaluasi organoleptisnya dan indek biasnya. Selanjutnya minyak atsiri di formulasikan dalam basis vanishing cream dengan konsentrasi, formula I : $20 \% \mathrm{v} / \mathrm{b}$; formula II : $30 \% \mathrm{v} / \mathrm{b}$ dan formula III : 40\% v/b. Ketiga formula tersebut kemudian diuji sifat fisiknya yang meliputi uji daya lekat dan daya sebar serta selanjutnya diuji daya repelan terhadap nyamuk Aedes aegypti betina sebanyak 20 ekor per kandang dengan probandus tangan relawan berjenis kelamin perempuan sebanyak 7 orang. Data yang diperoleh selanjutnya dianalisa dengan menggunakan statistik kolmogorov-smirnov dan uji t-test (main- whitney), dengan taraf kepercayaan $95 \%$. Hasil yang diperoleh menunjukkan

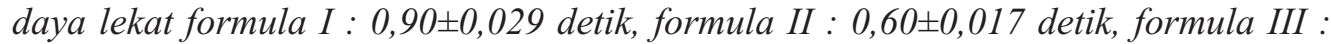

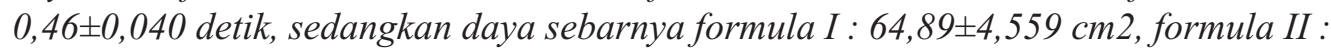

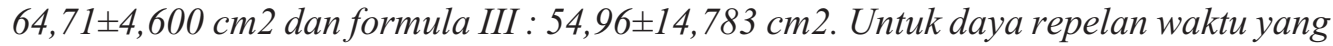


paling lama memberikan penolakan adalah formula III yaitu : 3014,2士20,163 detik atau 50,23 menit karena dengan meningkatnya konsentrasi minyak atsiri sere maka daya repelan makin meningkat.

Kata kunci : Vanishing Cream,Repelan, minyak atsiri sere (Cymbopogon citratus (D.C) Stapf.), Aedes aegypti betina

\section{Abstract}

Essential oil of sere leaf has been proven as repellant against mosquitoes. This research aims to know about the influence of concentration sere essential oil (Cymbopogon citratus (DC) Stapf) in a vanishing cream bases to physical properties and repellant testing against female Aedes aegypti mosquitoes. Essential oil of sere (Cymbopogon citratus (DC) Stapf) was isolated with steam water distillation and was evaluated the organoleptic appearance and refraction index. Furthermore, the essential oils were formulated in a vanishing cream base with the different formulas, contain formula I: $20 \% \mathrm{v} / \mathrm{w}$; formula II: $30 \% \mathrm{v} / \mathrm{w}$ and formula III: $40 \% \mathrm{v} / \mathrm{w}$. Then this three formulas were evaluated for physical properties including adhesive, dispersive and the repellent activity testing against female Aedes aegypti mosquitoes amount of twenty mosquitoes per cage while seven female volunteers as the probandus. The data have been analyzed using Kolmogorov-Smirnov test and t-test (Main-Whitney), with 95\% signifancy level. The results were obtained that the adhesion of formula I: $0.90 \pm$ 0.029 seconds, formula II: $0.60 \pm 0.017$ seconds, formula III: $0.46 \pm 0.040$ seconds, while the dispersion of formula I is $64.89 \pm 4.559 \mathrm{~cm}^{2}$, the formula II is $64.71 \pm 4.600 \mathrm{~cm}$ ${ }^{2}$ and the formula III is $54.96 \pm 14.783 \mathrm{~cm}^{2}$. The longest time repellent was formula III showed $3014.2 \pm 20.163$ seconds or 50.23 minutes. It was concluded that the increase of concentration essential oils of sere leaf followed by the increase of repellant activity.

Keywords: Vanishing Cream, Repellant, sere essential oil (Cymbopogon citratus (DC) Stapf.), female Aedes aegypti mosquitoes 


\section{PENDAHULUAN}

Demam berdarah merupakan salah satu masalah utama bagi negaranegara yang memiliki iklim tropis salah satunya adalah negra Indonesia. Sudah banyak penduduk Indonesia meninggal akibat demam berdarah. Beberapa daerah di Indonesia merupakan daerah endemik demam berdarah. Penyebab utama terjadinya demam berdarah adalah adanya vektor yaitu nyamuk Aedes aegypty. Banyak cara yang sudah dilakukan pemerintah maupun masyarakat sendiri dalam rangka mencegah terjadinya demam berdarah yaitu dengan penyemprotan DEET, penggunaan kelambu dan penggunaan abate untuk mencegah perkembangan jentik nyamuk, hal ini masih kurang efektif, karena terjadinya demam berdarah diakibatkan kontak antara vektor dengan tubuh seseorang melalui proses gigitan dan ini bisa terjadi dimanapun kita berada.

Sekarang yang banyak dilakukan oleh masyarakat dalam menanggulangi kontak antara vektor dengan tubuh adalah dengan penggunaan repelan (anti nyamuk) yang dioleskan pada kulit agar terhindar dari gigitan nyamuk. Repelan yang ada dipasaran hampir semua mengandung bahan-bahan berbahaya, salah satunya adalah Diethyltoluamide atau DEET. Sifat DEET ini sangat korosif, sehingga bisa menyebabkan iritasi kulit. Dampak yang dirasakan langsung akibat pemakaian produk anti nyamuk berbeda-beda pada setiap individu, terutama pada anak-anak. Umumnya anak akan merasakan sesak nafas, batuk-batuk, pusing, mual, hingga pingsan. Dalam jangka panjang pada pemakaian produk anti nyamuk terusmenerus setiap hari bisa menimbulkan kanker paru dan kanker kulit dalam jangka waktu 5-10 tahun (Anonim, 2007).

Dampak negatif dalam penggunaan repelan mengandung insektisida adalah residunya yang sulit terdegradasi sehingga membahayakan bagi pengguna maupun lingkungan. Untuk itu maka perlu dilakukan penelitian mengenai bahan-bahan repelan yang aman. Salah satu bahan alam yang sering digunakan sebagai repelan adalah minyak sere (Cymbopogon citratus (D.C) Stapf). Tanaman sere telah digunakan sebagai repelan alami sejak lama yang bekerja dengan cara memutuskan ketertarikan nyamuk terhadap manusia karena efek repelan itu sendiri. Atas dasar inilah maka perlu dilakukan penelitian dan pengembangan sediaan repelan yang berasal dari minyak atsiri daun sere (Cymbopogon citratus (D.C) Stapf) sebagai alternatif repelan alami. Menurut penelitian Kripsamaya (2011), yang berjudul daya tolak repelan minyak sere terhadap nyamuk Aedes aegypti betina, kemampuan repelan minyak sere adalah 8299,22 detik

Untuk meningkatkan acceptabilitas minyak atsiri sere dibuat sediaan vanishing cream, yaitu suatu sediaan setengah padat, berupa emulsi mengandung air tidak kurang dari $60 \%$ dan dimaksudkan untuk pemakaian luar. Krim akan rusak jika terganggu sistem campurannya yang dapat disebabkan perubahan suhu dan perubahan salah satu fase secara berlebihan. Daun sere mempunyai minyak atsiri yang tidak tahan panas dan ditujukan untuk pemakaian luar tubuh sehingga sangat tepat untuk dibuat sediaan vanishing cream. Dalam penelitian ini konsentrasi minyak 
atsiri sere dalam vanishing cream dibuat bervariasi bertujuan untuk diperoleh vanishing cream yang paling stabil dan memiliki sifat fisik yang baik serta daya repelan yang paling lama.

\section{METODE PENELITIAN}

\section{Bahan}

Bahan yang digunakan dalam penelitian ini adalah : daun sere (Cymbopogon citratus (D.C) Stapf) yang diambil dari Borobudur kabupaten Magelang Jawa Tengah, aquades, etanol $96 \%$, larutan gula $10 \%$, Asam stearat, malam putih, vaselin putih, trienolamin, dan propilen glikol.

\section{Alat-alat}

Alat yang digunakan dalam penelitian ini antara lain destilator uap dan air, Refraktometer ABBE (2WAJ), Rheon 1 viscotester VT-04, alat-alat gelas, sangkar nyamuk serta aspirator.

\section{Hewan Uji dan Probandus}

Hewan uji yang digunakan adalah nyamuk Aedes aegypti betina usia 7-24 hari diambil dari laboratorium Parasitologi Fakultas Biologi UGM. Probandus yang digunakan adalah tangan dari relawan yang berjenis kelamin perempuan sebanyak 7 orang.

\section{JALANNYA PENELITIAN}

\section{Isolasi Minyak Atsiri}

Daun sere yang akan diambil minyak atsirinya berasal dari Borobudur kabupaten Magelang setelah disortasi dan diangin-angin kemudian didestilasi secra uap dan air untuk mengambil minyaknya. Minyak atsiri yang diperoleh belum murni sehingga airnya harus dipisahkan dengan ditambah Na2SO4 anhidrat (Anonim, 1985). Waktu destilasi yaitu 4 jam setelah tetesan pertama, dengan kecepatan alir destilasi $\pm 4 \mathrm{ml} /$ menit. Minyak atsiri hasil destilasi diukur volumenya dan ditampung pada wadah gelap, tertutup rapat, dilapisi alumunium foil agar terlindung cahaya dan disimpan ditempat sejuk. Setelah diperoleh minyak atsirinya maka dilakukan uji organoleptis minyak atsiri meliputi : uji organoleptis, uji indek bias dan penetapan berat jenis minyak atsiri.

\section{Pembuatan Vanishing Cream Minyak Atsiri Sere}

Vanishing cream minyak atsiri sere berbagai variasi konsentrasi dibuat dengan cara mencampurkan minyak atsiri sere konsentrasi $20 \%(\mathrm{v} / \mathrm{b}$ ) (formula I), $30 \%(\mathrm{v} / \mathrm{b}$ ) (formula II), dan $40 \%(\mathrm{v} / \mathrm{b}$ ) (formula III), kedalam basis vanishing cream sebanyak 5 gram dalam kondisi dingin dan formula dapat dilihat pada tabel I. Melelehkan malam putih, asam stearat dan vaselin putih diatas penangas air pada suhu $75^{\circ} \mathrm{C}$. Trietanolamin dan propilenglikol dilarutkan dalam air hangat suhu $75^{\circ} \mathrm{C}$. Campuran TEA dan propilenglikol tersebu kemudian dimasukan ke dalam lelahan malam putih, asam sterarat dan vaselin putih lalu aduk sampai homogen dalam mortir hangat. Setelah krim dingin kemudian tambahkan minyak atsiri sere ke dalam krim. 
Tabel I. Formula vanishing cream minyak atsiri sere (Cymbopogon citratus (D.C) Stapf).

\begin{tabular}{|c|l|c|c|c|}
\hline No. & \multicolumn{1}{|c|}{ Nama Bahan } & Formula I & Formula II & Formula III \\
\hline 1 & Asam stearat & $150 \mathrm{~g}$ & $150 \mathrm{~g}$ & $150 \mathrm{~g}$ \\
2 & Malam putih & $20 \mathrm{~g}$ & $20 \mathrm{~g}$ & $20 \mathrm{~g}$ \\
3 & Vaselin putih & $80 \mathrm{~g}$ & $80 \mathrm{~g}$ & $80 \mathrm{~g}$ \\
4 & TEA & $15 \mathrm{~g}$ & $15 \mathrm{~g}$ & $15 \mathrm{~g}$ \\
5 & Propilen glikol & $80 \mathrm{~g}$ & $80 \mathrm{~g}$ & $80 \mathrm{~g}$ \\
6 & Aquadest & $655 \mathrm{~g}$ & $655 \mathrm{~g}$ & $655 \mathrm{~g}$ \\
7 & Minyak sere & $20 \% \mathrm{v} / \mathrm{b}$ & $30 \% \mathrm{v} / \mathrm{b}$ & $40 \% \mathrm{v} / \mathrm{b}$ \\
\hline
\end{tabular}

Uji Efek Repelan Vanishing cream minyak sere

Penelitian dilakukan secara eksperimental. Sangkar yang digunakan berukuran $20 \times 20 \times 20 \mathrm{~cm}$ dengan lubang sirkuler berdiameter $15 \mathrm{~cm}$, berisi 20 ekor nyamuk Aedes aegypti betina dewasa yang belum pernah digigitkan, dipuasakan sehari sebelum percobaan. Pada tangan yang akan diolesi sediaan dipastikan bebas dari pengaruh bahan kimia lainnya dengan cara mencuci tangan dengan sabun selanjutnya dibilas dengan etanol $96 \%$ dan didiamkan selama $\pm 2-3$ menit. Ketika repelan yang mengandung minyak atsiri yang dioleskan pada kulit, minyak atsiri akan meresap kekulit dan bercampur dengan senyawa-senyawa yang merupakan atraktan bagi nyamuk Aedes aegypti. Kemudian campuran senyawa tersebut menguap dan menimbulkan bau yang dideteksi oleh chemoreseptor nyamuk, yang dilanjutkan oleh impuls syaraf dan diterjemahkan oleh otak nyamuk. Berdasarkan hal tersebut, maka nyamuk akan menghindar atau tidak menggigit (Anonim, 2004). Untuk uji repelan peneliti mengacu pada metode yang dilakukan oleh Fradin dan Day (2002) dalam penelitiannya "Comparative Efficacy of Insect Repellent against Mosquito Bites".

\section{Uji Sifat Fisik Vanishing Cream Minyak Atsiri Sere}

Dalam menjamin kualitas farmasetik, sediaan yang dibuat harus memenuhi beberapa parameter fisik yang meliputi daya sebar, viskositas, dan daya lekat Uji sifat fisik repelan dilakukan setelah dilakukan uji anti nyamuk pada repelan minyak atsiri sere dalam basis Vanishing cream dengan berbagai konsentrasi.

\section{a. Uji daya sebar}

Setengah $(0,5)$ gram sediaan repelan diletakkan diatas kaca bulat berskala, kemudian ditutup dengan menggunakan kaca bulat yang tidak berskala yang telah diketahui bobotnya selama 1 menit, dicatat diameter penyebarannya, dilanjutkan dengan beban 50 gram, 100 gram, dicatat diameter penyebaran repelan, dilakukan replikasi sebanyak 3 kali. 


\section{b. Uji daya lekat}

Uji daya lekat dilakukan dengan cara sediaan repelan diratakan pada objek glas dengan ukuran kurang lebih 3 $\mathrm{cm} \times 2 \mathrm{~cm}$, kemudian ditutup dengan objek glass lain, ditekan dengan beban seberat $1 \mathrm{~kg}$ selama 5 menit. Objek glass dipasang pada alat uji dilepas dengan beban seberat 80 gram dan waktu yang diperlukan untuk memisahkan kedua objek glass tersebut dicatat. Pengujian dilakukan sebanyak 3 kali untuk masingmasing konsentrasi.

\section{Analisis Data}

Data waktu aktivitas repelan dan data hasil uji sifat fisik (daya lekat, daya sebar dan viskositas) repelan diuji homogenitas dan test Kolmogorovmirnov. Bila data terdistribusi normal pada test Kolmogorov-smirnov $(\alpha \geq$ $0,05)$ dan homogen pada uji homogenitas $(\alpha \geq 0,05)$, maka dilakukan uji parametrik one way Anova dan post hock test. Apabila tidak sesuai dengan ketentuan tersebut, dilanjutkan uji non parametrik Kruskal-Wallis dan Mann Whitney. Data berbeda bermakna bila pada uji parametrik atau pada uji non parametrik $\alpha \geq 0,05$.

\section{HASIL DAN PEMBAHASAN}

\section{Hasil Pembuatan Minyak Atsiri Daun Sere}

Hasil destilasi daun sere sebanyak $20,25 \mathrm{~kg}$ diperoleh minyak atsiri sebanyak $65,80 \mathrm{ml}$. Rendemen yang diperoleh sebesar : $65,80 \mathrm{ml} / 20250 \mathrm{~g} \mathrm{x} \mathrm{100 \%}$ $=0,325 \% \mathrm{v} / \mathrm{b}$.

\section{Uji Sifat Fisik Minyak Atsiri}

Sifat fisik minyak atsiri adalah salah satu parameter konstan yang diukur pada kondisi yang tetap, sifat fisik minyak atsiri ini digunakan untuk mengetahui kemurnian minyak atsiri dan menentukan mutu minyak atsiri (Anonim, 1985). Hasil uji sifat fisik minyak atsiri meliputi:

a. Hasil uji organoleptis: minyak atsiri daun sere mempunyai bau khas aromatik, rasa pedas tajam dan berwarna kuning jernih.

b. Penetapan indek bias merupakan salah satu cara untuk menguji sifat fisik minyak atsiri yang bertujuan untuk menguji kemurnian minyak atsiri. Penentuan indek bias minyak atsiri daun sere dilakukan di Laboratorium Kimia Organik Universitas Ahmad Dahlan. Hasil penetapan indeks bias minyak atsiri daun sere adalah 1,481 pada suhu $31,1^{\circ} \mathrm{C}$. Dalam buku "The Essential Oil" dicantumkan bahwa minyak atsiri daun sere adalah 1,4842 1,4888 pada suhu $20^{\circ} \mathrm{C}$. Hal ini menunjukkan bahwa indeks bias minyak atsiri daun sere sesuai dengan standar (Guenther, 1952).

Uji pendahuluan atau orientasi ini dilakukan bertujuan untuk menemukan formula terbaik berdasarkan pada sifat fisik vanishing cream khususnya stabilitas creamnya. Dengan stabilnya sifat fisik vanishing cream maka diharapkan akan memberikan efek repelan yang lebih baik. Dari hasil orientasi peneliti menetapkan formula I dengan konsentrasi $20 \% \mathrm{v} / \mathrm{b}$, formula II $30 \% \mathrm{v} / \mathrm{b}$ dan formula III $40 \% \mathrm{v} / \mathrm{b}$, sedangkan 
konsentrasi $45 \% \mathrm{v} / \mathrm{b}$ cream pecah atau tidak tercampurkan.

\section{Hasil Uji Sifat Fisik Vanishing Cream Minyak Atsiri Sere}

Ketiga formula tersebut maka selanjutnya dilakukan uji sifat fisik sediaannya yang meliputi uji daya lekat, uji daya sebar dan daya repelan dari vanishing cream tersebut.. Hasil uji daya lekat dapat dilihat pada tabel II. dan III memiliki keberbedaan pada jumlah aquadestnya disesuaikan dengan jumlah minyak atsiri yang ditambahkan agar bobot tetap 5 gram. Data pada tabel I menunjukkan daya lekat basis formula III diperoleh daya lekat paling lama yaitu $1,67 \pm 0,213$ detik tetapi setelah ditambahkan dengan minyak atsiri sebanyak $40 \% v b$ maka dengan penambahan minyak atsiri maka akan menurunkan kemampuan lekatnya menjadi

Tabel II. Hasil uji daya lekat vanishing cream minyak atsiri sere dan basis

\begin{tabular}{|c|c|c|c|c|c|c|}
\hline \multirow{2}{*}{ No. } & \multicolumn{7}{|c|}{ Daya Lekat Vanishing cream ( detik ) } \\
\cline { 2 - 7 } & Formula I & Formula II & Formula III & Basis FI & Basis FII & Basis FIII \\
\hline 1 & 0,93 & 0,58 & 0,51 & 1,35 & 0,73 & 1,85 \\
\hline 2 & 0,92 & 0,62 & 0,44 & 1,28 & 0,64 & 1,54 \\
\hline 3 & 0,87 & 0,59 & 0,48 & 1,25 & 0,48 & 1,43 \\
\hline 4 & 0,88 & 0,60 & 0,42 & 1,27 & 0,49 & 1,84 \\
\hline $\mathrm{X} \pm \mathrm{SD}$ & $0,90 \pm 0,029$ & $0,60 \pm 0,017$ & $0,46 \pm 0,040$ & $1,29 \pm 0,043$ & $0,59 \pm 0,121$ & $1,67 \pm 0,213$ \\
\hline
\end{tabular}

\section{Keterangan :}

Formula I : Vanishing cream dengan minyak atsiri sere $20 \% \mathrm{v} / \mathrm{b}$

Formula II : Vanishing cream dengan minyak atsiri sere $30 \% \mathrm{v} / \mathrm{b}$

Formula III : Vanishing cream dengan minyak atsiri sere $40 \% \mathrm{v} / \mathrm{b}$

Basis FI : Basis Formula I belum ada minyak atsiri sere

Basis FII : Basis Formula II belum ada minyak atsiri sere.

Basis FIII : Basis Formula III belum ada minyak atsiri sere

Dalam uji daya lekat ada perbedaa formula I, II dan III dimana perbedaan tersebut terletak pada konsentrasi minyak atisirinya sedangkan basis I, II
$0,46 \pm 0,040$ detik. Data tersebut juga terlihat pada basis formula I sebelum ditambah minyak atsiri daya lekat menunjukkan 1,29 $\pm 0,043$ detik dan setelah ditambah minyak sebanyak 20 $\% \mathrm{v} / \mathrm{b}$ maka daya lekatnya menjadi $0,90 \pm 0,029$ detik, ini menunjukkan bahwa dengan penambahan minyak atsiri maka akan menurunkan daya lekat karena ada penurunan konsistensi vanishing cream. Data formula I lebih lama daya lekatnya dibanding formula II dan III, hal ini disebabkan jumlah minyak atsiri yang ada di formula I lebih sedikit. Dengan semakin tinggi konsentrasi minyak atsiri sere maka akan mempengaruhi konsistensi dan kekentalan vanishing cream sehingga kemampuan daya lekatnya semakin menurun. Tabel 
kemampuan daya lekat dapat dilihat pada gambar 1.

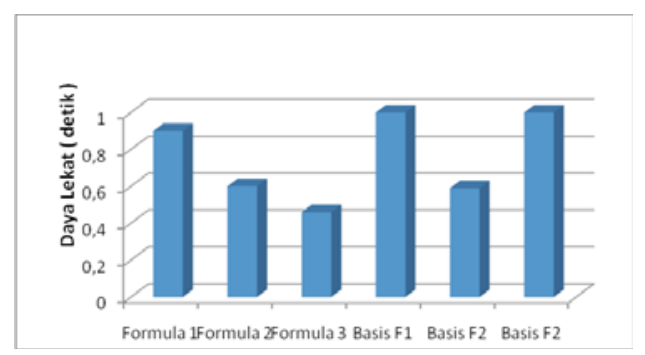

Gambar I. Grafik hasil uji daya lekat vanishing cream optimum pada formula II. Tabel daya sebar dapat dilihat pada tabel III.

Keterangan :

Formula I :Vanishing cream dengan minyak atsiri sere $20 \% \mathrm{v} / \mathrm{b}$

Formula II : Vanishing cream dengan minyak atsiri sere $30 \% \mathrm{v} / \mathrm{b}$

Formula III : Vanishing cream dengan minyak atsiri sere $40 \% \mathrm{v} / \mathrm{b}$

Basis FI : Basis Formula I belum ada minyak atsiri sere

Tabel III. Hasil uji daya sebar vanishing cream minyak atsiri sere dan basis

\begin{tabular}{|c|c|c|c|c|c|c|}
\hline \multirow{2}{*}{ No. } & \multicolumn{5}{|c|}{ Daya Sebar Vanishing Cream ( cm2) } \\
\cline { 2 - 7 } & Formula I & Formula II & Formula III & Basis FI & Basis FII & Basis FIII \\
\hline 1 & 58,06 & 62,18 & 40,13 & 20,42 & 35,77 & 14,84 \\
\hline 2 & 67,17 & 62,18 & 75,39 & 20,74 & 35,45 & 14,51 \\
\hline 3 & 67,17 & 62,88 & 53,43 & 25,50 & 33,99 & 15,20 \\
\hline 4 & 67,17 & 71,59 & 50,87 & 21,23 & 35,27 & 15,06 \\
\hline $\mathrm{X} \pm \mathrm{SD}$ & $64,89 \pm 4,556$ & $64,71 \pm 4,600$ & $54,96 \pm 14,783$ & $21,97 \pm 2,380$ & $35,27 \pm 0,870$ & $14,90 \pm 0,300$ \\
\hline
\end{tabular}

Secara teoritis formula III seharusnya memiliki daya sebar yang lebih besar dibanding formula I dan II karena konsentrasi minyak atsiri sere lebih banyak sehingga dengan penambahan minyak atsiri sere kekentalan semakin berkurang, akan tetapi apabila dilihat dari daya sebar basis formula I, II dan III menunjukkan bahwa daya sebar basis yang paling rendah adalah basis formula III. Hal ini kemungkinkan disebabkan perbandingan antara emulgator minyak dan emulgator air tidak seimbang karena adanya penambahan minyak atsiri secara ekternal tanpa diimbangi dengan penambahan emulgator minyak. Batas kemampuan emulgator kemungkinan
Basis FII : Basis Formula II belum ada minyak atsiri sere.

Basis FIII : Basis Formula III belum ada minyak atsiri sere

Hasil analisa statistik menunjukkan bahwa formula I dan II menunjukkan berbeda tidak signifikan daya sebarnya, dimana ditunjukkan harga $\mathrm{p}>0,05$ $((\mathrm{p}=0,886))$ sedangkan formula I dan III $(\mathrm{p}=0,343)$, formula II dan III $(\mathrm{p}=0,343)$, berarti daya sebar ketiga formula menunjukkan berbeda signifikan. Dengan adanya penambahan minyak atsiri sere yang berbeda jumlahnya tidak mempengaruhi daya sebarnya selama pada batas kemampuan emulgator. Sedangkan basisnya memiliki tingkat keberbedaan 
yang signifikan. Hal ini berkaitan dengan jumlah air digunakan dalam pembuatan vanishing cream dikurangi dengan jumlah minyak atsiri yang ditambahkan sehingga basis I, II dan III kekentalannya berbeda-beda. Hal ini bertujuan agar jumlah vasnishing cream yang diperoleh bobotnya selalu sama. Grafik uji daya sebar vanishing cream dan basis dapat dilihat pada gambar 2 .

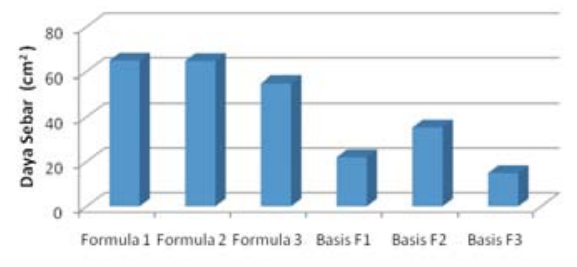

Gambar 2. Grafik hasil uji daya sebar vanishing cream dan basis

\section{Uji Daya Repelan Terhadap Nyamuk Aedes aegypti Betina}

Data hasil uji repelan dapat dilihat pada tabel III, pada tabel tersebut formula III memiliki kemampuan penolakan nyamuk yang lama dibanding formula I dan II serta basis yaitu $3014,2 \pm 20,163$ detik. Formula III memiliki daya repelan hampir satu jam karena mengandung minyak atsiri sere sebanyak $40 \% \mathrm{v} / \mathrm{b}$, sedangkan formula I dan II daya repelan berturut-turut adalah $54,71 \pm 2,263$ detik dan $25,17 \pm 2,042$ detik. Perbedaan kemampuan repelan ini dipengaruhi oleh jumlah minyak atsiri yang masih terkandung dalam sediaan. Dimungkinkan di formula II lebih rendah karena minyak atsiri sebagian sudah menguap dalam proses pencampuran dengan basis vanishing creamnya.

Hasil statistik menunjukkan nilai signifikansi $\mathrm{p}<0,05$ sehingga disimpul kan dari statistik ini bahwa baik formula I, II, dan III serta basis menunjukkan perbedaan signifikan, artinya ada perbedaan efek repelannya. Hasil penelitian menunjukkan bahwa formula III sangat memiliki daya repelan yang paling lama yaitu $3014,2 \pm 20,163$ detik atau hampir satu jam. Hasil penelitian ini masih menunjukkan efek repelan yang masih rendah dibandingkan efek repelan pada formula cold cream dimana konsentrasi minyak atsiri $10 \% \mathrm{v} / \mathrm{b}$ memberikan efek repelan selama 145,400 menit atau hampir 2 jam (Pranita, 2009). Perbedaan ini disebabkan adanya perbedaan basis vanishing cream dan cold cream dalam penelitian Pranita melakukan optimasi emulgator pada sediaan cold cream, sehingga dengan komposisi emulgator yang optimum maka akan menghasilkan sediaan yang baik serta sifat fisik dan daya repelan juga meningkat, sedangkan dalam penelitian vanishing cream basis diperoleh berdasarkan formula standar tanpa menambah emulgator secara ekternal hal ini yang memungkinkan terjadinya perbedaan daya repelannya. 
Tabel III. Hasil uji daya repelan vanishing cream minyak atsiri sere dan basis

\begin{tabular}{|c|c|c|c|c|c|c|}
\hline \multirow{2}{*}{ No. } & \multicolumn{6}{|c|}{ Daya Lekat Vanishing Cream (detik ) } \\
\cline { 2 - 7 } & Formula I & Formula II & Formula III & Basis FI & Basis FII & Basis FIII \\
\hline 1 & 50,53 & 26,93 & 3018,60 & 3,00 & 10,00 & 13,00 \\
\hline 2 & 59,87 & 22,93 & 3031,80 & 2,00 & 13,70 & 10,70 \\
\hline 3 & 53,73 & 25,64 & 2992,20 & 2,70 & 3,70 & 5,70 \\
\hline $\mathrm{X} \pm \mathrm{SD}$ & $54,71 \pm 2,263$ & $25,17 \pm 2,042$ & $3014,2 \pm 20,163$ & $2,57 \pm 0,513$ & $9,13 \pm 5,056$ & $9,8 \pm 3,732$ \\
\hline
\end{tabular}

Formula I : Vanishing cream dengan minyak atsiri sere 20 $\% \mathrm{v} / \mathrm{b}$

Formula II : Vanishing cream dengan minyak atsiri sere 30 $\% \mathrm{v} / \mathrm{b}$

Formula III : Vanishing cream dengan minyak atsiri sere 40 $\% \mathrm{v} / \mathrm{b}$

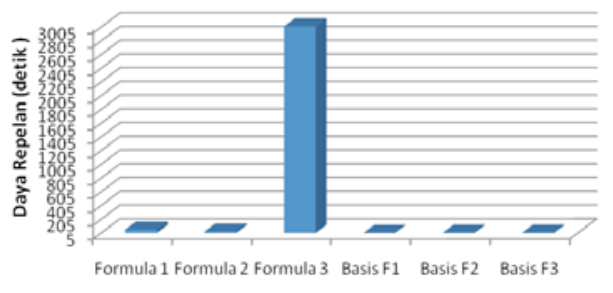

Basis FI : Basis Formula I belum ada minyak atsiri sere

Basis FII : Basis Formula II belum ada minyak atsiri sere.

Basis FIII : Basis Formula III belum ada minyak atsiri sere

Dari gambar 3 dapat dilihat grafik daya repelan vanishing cream minyak atsiri sere dan basis, menunjukkan bahwa formula III memiliki daya repelan yang paling lama dibanding formula I dan II serta basis. Secara fisik dapat dilihat vanishing cream formula III memiliki bau minyak sere yang menyengat dibanding formula I dan II sehingga ini mempengaruhi daya repelannya

Gambar 3. Grafik hasil uji daya repelan vanishing cream minyak sere dan basis

\section{KESIMPULAN DAN SARAN}

\section{Kesimpulan}

Minyak atsiri sere (Cymbopogon citratus (D.C) Stapf) dapat dibuat sediaan vanishing cream dengan konsentrasi minyak serenya $20 \% \mathrm{v} / \mathrm{b} ; 30 \% \mathrm{v} / \mathrm{b}$ dan 40 $\% \mathrm{v} / \mathrm{b}$, lebih dari $45 \% \mathrm{v} / \mathrm{b}$ sediaan vanishing cream pecah. Penambahan minyak atsiri sere (Cymbopogon citratus (D.C) Stapf) mempengaruhi daya lekat dengan semakin banyak konsentrasi minyak sere maka daya lekat semakin cepat, sehingga formula I lebih lama daya lekatnya dibanding formula II dan III, Daya sebar dari formula I, II dan III menunjukkan hasil tidak ada perbedaan secara signifikan dari setiap formula vanishing, dimana formula I $64,89 \pm 4,556$ 
$\mathrm{cm}^{2}$, formula II $64,71 \pm 4,600 \mathrm{~cm}^{2}$, dan formula III $54,96 \pm 14,783 \mathrm{~cm}^{2}$. Formula yang memiliki kemampuan daya repelan terlama dalah formula III dengan waktu penolakan $3014,2 \pm 20,163$ detik atau 50,23 menit, sedangkan formula I dan II daya repelan dibawah 1 menit.

\section{Saran}

1. Perlu dilakukan optimasi formula vanishing cream minyak atsiri sere Cymbopogon citratus (D.C) Stapf) dengan penambahan emulgator, sehingga dapat meningkatkan stabilitas sediaan dan efek repelannya.

2. Perlu dilakukan uji stabilitas vanishing cream berkaitan dengan stabilitas kandungan minyak atsiri sere (Cymbopogon citratus (D.C) Stapf) dalam sediaan.

\section{Ucapan Terima Kasih}

Mengucapkan terima kasih kepada DIPA Kopertis Wilayah V Yogyakarta yang telah membantu pendanaan sehingga terlaksana penelitian ini.

\section{DAFTAR PUSTAKA}

Anonim, 2004, Informasi Penyakit Menular.

http://ppmplp.depkes.go.id 3 Maret 2004.
Anonim, 2007, Tanaman Pengusir Nyamuk.

http://www.HarianGlobal.com/ne ws. 12 Mei 2007.

Fradin, S.M., dan Day, F.D, 2002, Comparative Efficacy of Insect Repellents against Mosquito Bites, The New England Journal of Medicine, Chapel Hill Dermatology, Vol.347 : 13-18.

Guenther, 1952, The Essential Oil. Volume Five. Van Nostrand Reinhodl Company. New York.

Kripsamaya,G.L, 2011, Skripsi, Daya Tolak Pemakaian Repelan Minyak Sere (Oleum citronella) Terhadap Nyamuk Betina Aedes aegypti, Universitas Islam Indonesia Yogyakarta.

Pranita PR, 2009, Skripsi, Optimasi Tween 80 dan Span 80 Sebagai Emulgator dalam Basis Cold Cream Repelan Minyak Atsiri Daun Sere (Cymbopogon citratus (D.C) Stapf.) Terhadap Nyamuk Aedes aegypti Betina Serta Uji Sifat Fisik Dengan Metode Simplex Lattice Design, Universitas Ahmad Dahlan Yogyakarta. 